\title{
A terceira significação dos nomes universais na Logica Ingredientibus de Abelardo
}

The Third Meaning of Universal Names in Abelard's Logica Ingredientibus

\author{
Luiz Roberto Takayama \\ Professor adjunto do Departamento de Ciências Humanas \\ Universidade Federal de Lavras [UFLA]
}

\section{RESUMO}

Este artigo pretende fazer uma breve apresentação do platonismo náo-realista de Abelardo através da solução dada na Logica Ingredientibus à célebre "querela dos universais".

\section{PALAVRAS-CHAVE}

Abelardo; Logica Ingredientibus;

Platonismo; Querela dos universais.

\section{ABSTRACT}

This paper intends to show briefly the nonrealist platonism of Abelard through the solution given in Logica Ingredientibus to the famous "quarrel of the universals".

\section{KEY WORDS}

Abelard; Logica Ingredientibus;

Platonism; Quarrel of the Universals. 


\section{Introdução}

A formulação das questôes relativas ao problema dos universais revela já, desde sua origem, um parti pris não sem consequências à querela desencadeada a partir de então: a opção de Porfírio pela subsistência real dos universais, autorizada por Aristóteles ${ }^{1}$, deixa-se entrever na medida em que condiciona as perguntas subsequentes que propõe. ${ }^{2}$ Além disso, a assunção de tal realismo realiza-se excluindo a alternativa que considera os universais in intellectus, ou seja, como concepçóes do espírito. A correção dessa unilateralidade radical de Porfírio é efetuada em seguida por Boécio, reunindo ambas dimensóes ontológica e gnosiológica na alternativa de escolha, opondo-a doravante àquela que concebe os gêneros e as espécies como frutos da imaginatio.

Boécio percebeu, portanto, com aguda intuição, que o problema do universal não se resolvia recorrendo somente à dimensão ontológica, senão que era necessário considerar, além disso, sua dimensáo gnosiológica. Em síntese, enquanto a primeira pergunta porfiriana exclui a alternativa universal resultante de uma atividade intelectual e assume somente a alternativa universal subsistente ontologicamente, essa mesma pergunta, reformulada por Boécio, exclui a alternativa do universal resultante, não da atividade do intelecto, mas da imaginação e assume o universal que subsiste ontologicamente e que, além disso, é resultado de um processo intelectual (Bertelloni, 1995, p. 160).

Abelardo não se deixará afastar da autoridade ao mesmo tempo em que apresenta uma radical originalidade na abordagem e na soluçáo do problema. Como observa Bertelloni (1988, p. I2), “o recurso às autoridades interessa não tanto pelo que elas mesmas dizem senão pelo que Abelardo encontra nelas e as faz dizer”. O aporte original do magister palatinus ao introduzir a dimensão semântica ou linguística no tratamento da questáo náo contraria o que dizem ou o que fazem dizer as autoridades. Ao contrário, vê-se confirmado por elas, pois se o universal é um nome, ele significa, quodammodo, as coisas individuais e engendra uma intelecção, como indicava Boécio; ainda que separadas, as esferas da linguagem, das coisas e das ideias entretêm relaçôes determinadas, "os nomes significam as intelecçôes, mas dizem respeito às coisas" (Jolivet, 1982, p. 68).

As reflexôes sobre a linguagem trazidas por Abelardo, inovadoras na problematizaçáo da questão dos universais, concluía, dentro do quadro da chamada logica vetus,

\footnotetext{
1 É mesmo Abelardo que reconhece, na autoridade, esse estatuto reificante do universal: "Com efeito, o próprio Aristóteles aplica-o [o universal] às coisas, quando propunha logo antes da definiçáo do universal o seguinte: uma vez que algumas coisas são universais e outras singulares..."; contudo, nota imediatamente que essa mesma autoridade atribui o universal também às palavras: "Mas os nomes, também, são chamados de universais. Daí a afirmaçâo de Aristóteles: o gênero determina a qualidade quanto à substância, pois ele significa como algo ê" (Abelardo, I994, p. 46; doravante, citaremos essa obra como LI seguido do número de página).

2 "Assim, a opçấo porfiriana pelos universais como subsistentia condiciona as duas respostas seguintes, já que em cada uma delas, a condição de universal incorporal (segunda pergunta) e separado ou imanente (terceira pergunta) é precedida e condicionada pelo universal subsistens...” (Bertelloni, I995, p. 158).
} 
o já longo processo histórico-doutrinal inaugurado pelas perguntas de Porfírio. ${ }^{3}$ Contudo, é preciso dizer também que, ao mesmo tempo, as análises gramaticais e dialéticas introduzidas por Abelardo na apreciação do problema careciam de originalidade, se contempladas dentro do âmbito da tradição cultural que herdava. ${ }^{4}$ Se podemos dizer, com Jolivet (1982, p. 13), que "a filosofia de Abelardo é espontaneamente o produto de uma reflexáo sobre a linguagem”, de uma arte da linguagem por assim dizer, é preciso levar em conta as circunstâncias e as condiçóes em que se exerce.

A primazia das artes sermocinales ou artes do trivium sobre as artes reales ou artes do quadrivium caracteriza a história da cultura do ocidente até o século XII. ${ }^{5}$ Além disso, a filosofia de Abelardo é, sobretudo, uma filosofia de comentador, tendo em mãos as obras lógicas de Porfírio, Boécio e Aristóteles as quais deve, como bom dialético, interpretar frase por frase, escrutar palavra por palavra para a correta elucidação de textos que tratam, eles mesmos, de reflexôes acerca da linguagem ${ }^{6}$. Acrescente-se a isso a função pedagógica exercida por Abelardo, essencialmente uma técnica da linguagem, e constataremos que sua situação histórica, sua profissão assim como os textos de que dispóe e que comenta concorrem para que se incline para as artes do trivium. Por fim, uma última razão que ele mesmo oferece: náo basta ter distinguido os domínios ontológicos e gnosiológicos, aquele das coisas e aquele das ideias, é preciso também considerar aquele da linguagem: “[...] já reponta, além da coisa e da intelecção, uma terceira significação dos nomes” (Abelardo, 1994, p. 68).

Assim, a tripla significação dos universais deve levar em conta a dimensão ontológica indicada por Porfírio, assim como a dimensão intelectiva acrescentada por

3 A questão de se considerar que diversas doutrinas foram concebidas a partir das soluçôes da questão dos universais ou entáo que tais soluçóes eram dadas, junto às de outros problemas, na coerência de doutrinas cujas bases já haviam sido concebidas, traduz, respectivamente, duas avaliaçóes distintas quanto à posição da questão dos universais: a primeira, na esteira de Victor Cousin, a entende como a ocupaçáo fundamental e quase integral da filosofia medieval; a segunda, de Gilson, que a vê como um importante campo de batalha mas no qual os adversários já entravam munidos de todas as suas armas: "Metafísicas adversárias mediram suas forças concorrendo para ver quem saberia resolvê-lo [o problema dos universais] melhor, mas não nasceram das soluçôes que propunham para ele." (Gilson, I995, p. I63). Jolivet (1982, pp. 337-363) mostra que o não-realismo de Abelardo - recusando ver a realidade exclusivamente sob o modo de ser das coisas e introduzindo, por conseguinte, o conceito de status - está na base, como uma "intuição simples", tanto de suas análises semânticas (significaçáo dos universais), quanto dialéticas (dictum propositionis ); de sua ética (a questáo do pecado), bem como de sua teologia (a questáo da Trindade); e, possivelmente, associado ao seu próprio modo de vida (Abelardo como homem "urbano"?). Assim, acreditamos poder situar Jolivet mais próximo de Gilson.

4 "Convém assim ser prudente quando se fala de um período ainda mal explorado, e não se precipitar ao atribuir posiçôes definitivas aos autores. Todavia, não nos aventuremos lembrando que o ensinamento de Abelardo despertou um forte interesse: poder-se-ia daí presumir que ele apresentava algo notável. Ora, seu objeto não tinha nada de original: eram tratados da logica vetus, conhecidos de longa data" (Jolivet, 1982, p. 338).

5 Jolivet (1982, p. I4 e ss.) nos apresenta uma série de razóes e exemplos que mostram a preponderância das ciências da linguagem sobre as ciências das coisas nesse período da Idade Média: o cristianismo enquanto religiăo revelada por meio de textos simbólicos, suscitava, naturalmente, um privilégio ao estudo da significação do verbo e era já Santo Agostinho, na De doctrina christiana, que salientava a importância do estudo das línguas e da dialética para a elucidação dos textos sagrados; além disso, Boécio começa a ser descoberto por volta dos séculos X e XI dando um novo impulso à dialética.

6 Temos, entre outros, um claro exemplo desse modus operandi nas páginas iniciais da Logica Ingredientibus, quando o autor comenta, também no nível de palavras, a introdução da Isagoge de Porfírio (LI, pp. 33-39). 
Boécio, e, nisso, Abelardo não se distancia da autoridade. Entretanto, tais dimensôes são articuladas em função das exigências de um novo domínio, aquele da linguagem, ponto de partida de sua filosofia: novidade em relação ao pioneirismo de sua introduçáo formalizada no problema dos universais, tradicional na medida em que reflete a cultura de uma época quase que exclusivamente centrada sobre a gramática e a dialética, artes do trivium.

É através da linguagem que os pensamentos relativos às coisas são expressos e compreendidos; por outro lado, a linguagem é submetida a leis que lhe são próprias e que constituem justamente a matéria das disciplinas do trivium; há ainda uma ciência das palavras e de suas relações com as coisas (correspondências e desacordos). Instalando-se deliberadamente na linguagem, o dialético se encontra como em um centro donde se oferecem a ele as outras regióes do real; ele poderá e deverá analisar a partir daí os mecanismos do espírito e as relaçôes das coisas, como também, tanto em seu texto quanto em seu sentido, os escritos antigos e os textos sagrados. [...] A célebre doutrina dos universais só ganha seu sentido, nós o veremos, a partir da teoria da predicação, que se liga àquela da significação (Jolivet, 1982, p. 2I).

\section{Status non est res}

Após a crítica empreendida contra a tese realista do universal ${ }^{7}$, Abelardo reformula a célebre definição dada por Aristóteles no Peri Hermeneias:

Um vocábulo universal, entretanto, é aquele que, por sua descoberta, é apto para ser predicado de muitos tomados um a um, tal como este nome homem, que pode ser ligado com os nomes particulares dos homens segundo a natureza das coisas subordinadas às quais foi imposto (LI, p. 56).

O nome ou vocábulo universal assim definido se liga aos nomes particulares por predicação (coniunctio praedicationis) e, enquanto tal, à diferença da ligação por construção (coniunctio constructionis), "diz respeito à natureza das coisas e à demonstração da verdade de seu estado" ( $L I$, p. 58). ${ }^{8}$ A definição de universal dada por Abelardo é, portanto, estabelecida no plano da linguagem: os universais são nomes ou palavras que se ligam a outros nomes e palavras mas não de modo arbitrário e nem

\footnotetext{
7 A pars destruens da Logica Ingredientibus, ao que tudo indica, é dirigida particularmente contra as posiçóes de Guilherme de Champeaux, e, de modo geral, a corrente realista inaugurada por Porfírio, na qual Roscellino pode ser incluído, apesar de sua divergência (Bertelloni, I995, p. I6I-I66.). Partindo da evidência metafísica de que a realidade é constituída de coisas individuais irredutíveis entre si e da definição de universal dada por Aristóteles - "aquilo que é naturalmente apto para ser predicado de muitos" - a tese realista é reduzida ao absurdo. Com efeito, se o universal é uma subsistência real ele é uma res que, enquanto tal, é individual e, portanto, não pode ser universal, isto é, predicado de muitos. A interpretaçáo estritamente ontológica dos universais não logra resolver o problema; assim, "resta que confiramos essa universalidade apenas às palavras" ( $L I$, p. 56$)$.

8 Segundo Abelardo, a distinção entre a construção, considerada pelos gramáticos, e a predicaçáo, tratada pelos dialéticos, reside no fato de que apenas a segunda se condiciona a um correlato ontológico (natureza das coisas), enquanto à primeira basta que seja formada corretamente, isto é, segundo às regras gramaticais e, assim, manifeste uma intelecção, ainda que não mostre um estado de coisas. Deste modo, temos uma boa construção quando ligamos os termos homem e pedra ("homem é pedra"), mas não uma predicaçâo.
} 
apenas segundo as regras formalizadas da gramática — a força da predicação advém de sua correspondência com a realidade. Dito de outra maneira, os nomes universais "significam, de certo modo, coisas diversas por meio da denominação" ( $L I$, p. 6o): a palavra "homem" nomeia tanto Sócrates como Platão; há uma imposição (impositio) dos nomes universais a coisas distintas segundo um fundamento ontológico ou causa comum (causa communis).

Mas, se em sua crítica à primeira posição realista — identitas secundum essentiam - Abelardo concluía, fazendo jus à física, pela distinção radical das coisas tanto com relação à essência quanto às formas, interditando deste modo a concepção de uma res universalis, a doutrina da convenientia - variante da identitas secundum indiferentiam, segunda posição realista —, embora "aproximando-se mais da determinaçáo da coisa", equivocava-se na medida em que fazia coisas distintas combinaremse na "coisa" universal ( $L I$, p. 50). Na determinação da causa comum enquanto fundamento da imposição dos nomes universais, Abelardo assume a doutrina da convenientia, corrigindo-a, entretanto, em um ponto fundamental':

Cada um dos homens, distintos uns dos outros, embora difiram tanto pelas próprias essências quanto pelas formas [...] se reúnem naquilo que são homens [quod homines sunt]. Não digo no homem, já que nenhuma coisa é homem exceto uma coisa distinta, mas no ser homem [esse hominem] (LI, p. 6I, grifo nosso).

Assim, Sócrates e Platão se assemelham ou combinam um com outro em "algo" mas não em alguma "coisa”, já que toda coisa é individual, isto é, idêntica a si mesma e separada de tudo que não ela mesma. "Chamamos de estado de homem [status homini] o próprio ser homem, que não é uma coisa e que também denominamos causa comum da imposição do nome a cada um, conforme eles próprios se reúnem uns com os outros" (LI, pp. 6I-62). A convenientia entre Sócrates e Platáo realiza-se, portanto, a partir deles próprios, ou seja, o status diz respeito a cada indivíduo e, nesse sentido é uma natureza individual; trata-se de uma certa realidade da coisa mas que não é coisa; ser homem pode ser compreendido como a essência ou natureza de Sócrates e de Platão sob a condição de entendê-lo náo como uma res mas como o fato de que eles são aquilo que são, ou seja, homens.

O status, fundamento da função significativa do universal, é portanto uma natureza individual, ainda que não seja uma coisa; o "não realismo" de Abelardo, centro orgânico de sua filosofia, como quer Jolivet, deve ser entendido não como uma recusa pura e simples da realidade dos universais a favor de um suposto nominalismo, mas como um procedimento crítico de "dereificação" daquilo que constitui a natureza ou essência das coisas. Tal procedimento implica positivamente na concepção

9 "O erro do realismo não é o de reconhecer e sim de conceber mal a semelhança que existe entre as coisas" (Vignaux, 1931, col. 727). 
de um novo estatuto ontológico resultante de um alargamento daquela visão metafísica que não admitia, no plano da realidade, senão uma de duas alternativas excludentes, a saber, "ser coisa" ou não ser nada. ${ }^{10}$

\section{Solus, nudus, purus}

Tendo mostrado que as palavras universais significam ou denominam coisas singulares em razão de uma causa comum, Abelardo se empenha em satisfazer outra exigência imposta pelas autoridades: significar é engendrar uma intelecção (intellectus). Mas, para que uma intelecção seja válida, é preciso que ela se refira a alguma coisa subordinada (res subiecta). "No entanto", adverte Abelardo ( $L I$, p. 59), "no nome comum que é 'homem', nem o próprio Sócrates nem outro, nem a coleção inteira dos homens é racionalmente inteligida por força da palavra" de modo que, ao que tudo indica, a palavra universal parece não engendrar intelecção alguma.

Mas não é assim. De fato, eles significam, de certo modo, coisas diversas por meio da denominaçáo, não porém fixando uma intelecção procedente delas, mas pertinente a cada uma. Com esta palavra 'homem', tanto nomeia cada um deles por motivo de uma causa comum, isto é, que são homens, pelo que é denominada universal, como constitui uma certa intelecção comum, não própria, isto é, pertinente a cada um deles, dos quais concebe a semelhança comum (LI, p. 6o).

Cumpre notar que, se Abelardo distingue, com cuidado, entre pertinência e procedência, é porque, para ele, a intelecção é, antes de tudo, uma ação da alma que, junto a sensação e a imaginação, constituem os três graus do conhecimento humano assim entendido. ${ }^{11}$

A sensação se exerce somente através do corpo como instrumento e percebe aquilo que está nas coisas na medida em que elas estão efetivamente presentes. Tão-somente

\footnotetext{
10 "Há, portanto, uma coerência ontológica do mundo garantida por uma certa realidade das espécies e dos gêneros. Esta realidade, entretanto, não é aquela de uma coisa. Aquilo no qual se encontram os homens individuais, o esse hominem, não tem mais realidade do que aquilo em que se encontram as coisas animadas (cavalo ou asno) que não são homens: trata-se de um estatuto (status) que tem uma modalidade ontológica particular. Não é um nada (nihil), mas não é uma coisa (nulla res)" (De Libera, 1993, p. 324).

11 "Pode-se sentir sem imaginar, imaginar sem pensar; mas a imaginação supõe a sensaçáo, e não há intelecção sem imagem. Essas três formas do conhecimento são portanto escalonadas e náo justapostas" (Jolivet, p. 365). Poder-se-ia objetar que há um caso em que, ao que parece, há intelecção sem imagem: quando a coisa está presente ao mesmo tempo em que a sensação e, nessas circunstâncias, a coisa subordinada à intelecção não é uma forma (imagem) mas a verdadeira substância da coisa: "quando a alma sente e intelige ao mesmo tempo, por exemplo, quando discerne uma pedra, será que a intelecçáo ocupa-se também entấo com a imagem da pedra ou a intelecçáo e a sensaçáo ocupam-se ao mesmo tempo com a própria pedra? Ora, parece mais racional que, entâo a intelecção não precise da imagem, já que a verdade da substância está presente a ela” ( $L I$, p. 63). E o que parece indicar Wenin: "[...] a necessidade, para o conhecimento intelectual, de um termo intencional [imagem] diferente da coisa, mesmo quando esta está presente de maneira sensível, não é afirmada pelo autor; a opiniāo contrária lhe parece mais razoável” (Wenin, I982, p. 433). E é o próprio Jolivet (I982, pp. 368-369) que afirma: "nenhuma intelecçáo pode nascer se náo estiver fundada sobre outra coisa, sensaçáo ou imagem." De qualquer modo, ao que nos interessa aqui, a intelecção dos universais, nós o veremos, tem como coisa subordinada uma forma comum, definida como imagem da semelhança de muitos.
} 
pela sensação, não se conhece a natureza ou substâncias das coisas, mas apenas seus acidentes: através da visão, a largura e a altura de uma torre, por exemplo.

A imaginação constitui um grau superior de conhecimento na medida em que náo necessita de instrumentos corpóreos e nem da presença da coisa a que se dirige; basta-lhe apenas a semelhança da coisa, elaborada espontaneamente pelo espírito enquanto imagem que substitui a própria coisa em sua ausência. A imagem é uma coisa fictícia

Que o espírito elabora para si quando quer e como quer, como sáo aquelas cidades imaginárias vistas durante o sono ou como aquela forma de um edifício a ser construído que o artesão concebe como semelhança e modelo da coisa a ser produzida e que não podemos chamar nem de substância nem de acidente (LI, p. 63).

A intelecção, terceiro grau de conhecimento, é propriamente aquela ação da alma que faz aceder, ainda que de modo confuso, à natureza ou propriedades das coisas ${ }^{12}$. Ela diz respeito às coisas, ou à verdadeira substância das coisas, quando estas estão presentes simultaneamente à sensação, ou então concebe delas uma imagem ou forma quando estas se encontram ausentes.

A imagem concebida pelo espírito a partir de um nome universal é uma imagem ou forma comum a muitos indivíduos e, em razão dessa comunidade, leva à confusão: “'homem’ não significa diretamente nem Sócrates nem qualquer outro homem, já que nenhum é certificado por força do nome, ainda que ele nomeie a cada um deles" ( $L I$, p. 64). Contrariamente, o nome singular engendra a forma própria de um só; ele não só nomeia, mas determina a coisa a que se dirige. Mas, se como quer Boécio, uma intelecção é válida unicamente se tem uma coisa subordinada, é preciso admitir que a palavra universal significa, pois engendra uma intelecçáo, ainda que confusa, concebendo uma forma comum — res subiecta dos nomes universais.

Podemos também chamar de coisa subordinada à intelecção, quer a verdadeira substância da coisa, como quando ela está presente ao mesmo tempo que a sensação, quer a forma concebida de uma coisa qualquer, isto é, na ausência da coisa, quer esta forma seja, como dissemos, comum, quer própria; digo comum quanto à semelhança de muitos que ela retém, embora, por outro lado, seja considerada em si como uma coisa una ( $L I$, p. 65$)$.

Não obstante, se a intelecção engendrada pelos nomes universais não é vazia, ela também não é falsa e, além disso, faz conhecer as propriedades das coisas. É a teoria da abstração, tal como Abelardo a expõe, que traz uma luz a respeito da relação entre esse modo próprio da intelecção dos universais e a natureza das coisas.

Uma coisa individual, como por exemplo Sócrates, possui inúmeras propriedades: "a substância deste homem é corpo, é animal, é homem, é revestida de formas

12 "Ela [a intelecção] nos faz conhecer a natureza e as propriedades das coisas, imperceptíveis aos sentidos como à imaginaçáo [...]” (Jolivet, I982, p. 369). 
infinitas" ( $L I$, p. 69). A abstração é o poder que tem o espírito de dirigir sua atenção para uma dessas propriedades separadamente para considerar sua própria natureza. A conjunção, ao contrário, é um poder de síntese que une tais qualidades umas às outras. Ora, poder-se-ia concluir daí que as intelecçôes por abstração são falsas uma vez que "percebem a coisa de modo diferente de como subsiste", ou seja, inteligem separadamente propriedades que se encontram unidas na realidade ( $L I$, p. 70 ). De fato, elas seriam falsas sob duas circunstâncias: em primeiro lugar, se atentassem para propriedades ou naturezas que não pertencessem à coisa considerada, e, em segundo lugar, se admitíssemos que a coisa subsiste tal como é inteligida. No entanto, quando abstraímos apenas uma das propriedades de uma coisa, a corporeidade de Sócrates por exemplo, inteligimos algo que efetivamente está nele, ainda que nossa atenção não se dirija a tudo o que ele possui.

A intelecção por abstração pode se dizer legítima desde que se considere diferente o modo de inteligir do modo de subsistir. O erro consistiria em considerar como subsistindo separadas propriedades que são inteligidas separadamente. "Com efeito, esta coisa é inteligida separadamente da outra, mas náo como separada, pois, enfim, ela não existe em separado [...]" ( $L I$, p. 70 ). Assim, o espírito possui o duplo poder de unir coisas que existem separadas - Sócrates e Platão unidos por semelhança naquilo que são homens - e separar o que são unidos - a forma da matéria através da abstração. Mas, como afirma Boécio, em ambos os casos, sem se afastar da natureza da coisa, uma vez que se intelige aquilo que está na natureza da coisa. "Se assim não fora, não se trataria de razão mas de opinião, isto é, se a inteligência se desviasse do estado da coisa" ( $L I$, p. 7I).

As intelecçôes dos universais se dão sempre por abstração: quando se pronuncia ou se ouve a palavra "homem", nossa atençáo se dirige a apenas uma das naturezas ou propriedades que se encontram na imagem ou forma comum (res subiecta), a saber, a concepção confusa de animal racional mortal, deixando-se de lado os demais acidentes. Mas, deve-se acrescentar que as intelecções dos singulares também se dão por abstração, quando se diz, por exemplo, "este homem"; neste caso, atentamos àquela mesma natureza de homem separadamente das outras, mas referida a um determinado sujeito. Abelardo conclui:

Portanto, a intelecção dos universais é denominada com razão isolada [solus], nua $[$ nudus] e pura [purus]: isolada, sem dúvida, das sensaçôes porque não percebe a coisa como sensível; nua, quanto à abstraçáo de todas ou de algumas formas e completamente pura, quanto à distinção porque nenhuma coisa, quer seja matéria, quer seja forma, é certificada nela, razão pela qual chamamos acima uma concepção deste tipo confusa ( $L I$, p. 73$)$. 


\section{A terceira significação dos nomes}

Vimos até agora que os universais são nomes que significam coisas distintas, aquelas mesmas significadas pelos nomes singulares - nomeando-as através de uma predicação, tal como Aristóteles os define. A imposição do nome universal a essas coisas se fundamenta em uma semelhança nas quais elas se reúnem, isto é, numa causa comum definida como status, realidade dereificada que constitui a "essência" ou "natureza" das próprias coisas. Os universais engendram, ademais, uma intelecção não vazia - na medida em que concebe uma imagem ou forma comum que é a coisa subordinada à qual se dirige - , e não falsa, posto que realizada por abstraçáo, considerando de modo separado e confuso propriedades ou aspectos das coisas segundo sua natureza e seu status.

Assim, se Abelardo define os universais como nome, é porque prova o absurdo de considerá-los como subsistências reais (res), tal como admitia a corrente realista. personificada na figura de Guilherme de Champeaux. Contudo, enquanto nomes, os universais significam coisas e fixam intelecçóes que se relacionam com a realidade (status) dessas mesmas coisas através de uma forma comum, e, nesse sentido, não são apenas emissóes de ar, flatus vocis, como queria Roscellino. Ora, essa imagem ou forma comum concebida pelo espírito a partir do nome universal é chamada comum "quanto a semelhança de muitos que ela retém, embora, por outro lado, seja considerada em si como uma coisa una" (LI, p. 65, o itálico é nosso).

De modo análogo, o universal, enquanto palavra comum, "é comum pela designação na denominação de muitos", "embora seja em si mesma como que uma coisa una em essência" ( $L I$, p. 79$)$. Assim, não se poderia dizer que o nome universal significa também a forma comum concebida? É o que parece ser confirmado tanto pela autoridade quanto pela razão. Contudo, Abelardo introduz uma distinção sutil, mas não de menor importância, que parece ter passado desapercebida por essas mesmas autoridades: a intelecçáo, enquanto ato subjetivo, difere da imagem ou forma que concebe.

Todavia, assim como a sensação não é a coisa sentida para a qual se dirige, assim também a intelecção não é a forma da coisa que ela concebe [...] Alguns, entretanto, chamam-na de o mesmo que a intelecção [...]. Nós, porém, chamamos a imagem de semelhança da coisa. Mas nada impede que a intelecçáo, de certo modo, também seja chamada de semelhança, uma vez que evidentemente concebe aquilo que se denomina propriamente semelhança da coisa. Que nós dissemos, e com razão, que é diferente daquela ( $L I$, p. 62).

A imagem é semelhança $d a$ coisa, ainda que concebida pela intelecção; em termos mais contemporâneos, ela está do lado do noema e não da noese. ${ }^{13}$ "Mas, certamente, uma vez que nós admitimos que elas [as formas comuns] são diferentes das

\footnotetext{
13 "Mas, aquilo que encontra, e que os comentadores de Aristóteles não parecem se dar conta, é que a forma concebida não está do lado da noese; ela não é uma modalidade do ato subjetivo da intelecção. A forma fictícia é um ser intencional do lado do noema" (Wenin, 1982, p. 439).
} 
intelecçóes, já reponta, além da coisa e da intelecção, uma terceira significação dos nomes" (LI, p. 68).

A universalidade das palavras universais deve-se à multidão de coisas que elas significam por denominação, e é nesse sentido que a palavra universal é universal, ou seja, "predicado de muitos". Mas, em si mesma, é una em essência, donde sua unidade de significação que a distingue das palavras equívocas. Ora, essa unidade não pode provir, evidentemente, das coisas que nomeia, múltiplas e distintas, não menos das intelecçóes que suscita, atos subjetivos que, enquanto tais, são transitórios. Há, portanto, uma autonomia do modo de ser da linguagem tanto em relação às coisas, quanto em relação às intelecçôes. Mas, então, o que garante essa unidade de significaçáo autônoma, essa unidade de essência da palavra que constitui seu "ser de nome"? É preciso, para tanto, que a palavra universal signifique uma essência una, imutável, ideal. ${ }^{14}$ Tais devem ser, portanto, as características da forma comum.

Por intermédio da autoridade de Boécio, constata-se um desacordo entre Aristóteles e Platão que Abelardo pretende dirimir:

De fato, o que Aristóteles diz quanto aos universais subsistirem sempre nos sensíveis, o diz quanto ao ato, porque, evidentemente, aquela natureza que é o animal, designada pelo nome universal e, de acordo com isso, chamada universal por certa transferência, nunca é encontrada em ato a não ser na coisa sensível, mas Platão pensa que ela subsiste naturalmente em si mesma de tal modo que conservaria seu ser se não estivesse sujeita à sensaçáo e, de acordo com este ser natural é chamada pelo nome universal. Por conseguinte, o que Aristóteles nega quanto ao ato, Platão, o investigador da física, atribui à aptidão natural e, desse modo, não há discordância nenhuma entre eles ( $L I$, p. 8I).

Deve-se lembrar que tais autoridades são invocadas por Abelardo para a confirmação de que o nome universal designa a forma comum. Portanto, ela é aqui identificada à "natureza que é o animal" ou ao "ser natural", subsistente nos sensíveis, como quer Aristóteles, somente quanto ao ato, mas subsistindo naturalmente em si, como quer Platão, quando não sujeita à sensaçáo. A forma comum significada pelo nome universal é um ser natural, um ser de razão ideal, "não um ente perdido na diversidade das coisas sensíveis nem no fluxo dos atos da consciência" (Wenin, I982, p. 439).

O ser natural é imutável, ou seja, subtraído das vicissitudes do tempo: continuamos a compreender a proposição "não há rosas" pois, ainda que o nome não mais signifique por denominação, uma vez que não existam mais as coisas de que predique, ele continua a engendrar uma intelecção válida. A forma comum subsiste, intocada, mesmo quando não mais existem as coisas às quais se relaciona.

Assim, a unidade de significação do nome é garantida por uma forma comum, descrita por Abelardo, sob inspiração platônica, como um ser natural ideal. Invo-

${ }^{14}$ Que nos seja permitido dar um nome ao que acabamos de descrever: platonismo. 
cando, desta vez, a autoridade de Prisciano, Abelardo introduz uma dimensão propriamente teológica, identificando essa forma comum ou esse ser natural platônico inteligido a partir dos nomes universais às concepçóes comuns dos estados de coisas (status) presentes no pensamento divino: "Trata-se nesse passo de Deus como de um artesão a ponto de construir alguma coisa, que concebe de antemáo em sua alma a forma exemplar da coisa a ser construída [...]" (LI, p. 65). Contudo, adverte Abelardo, essa forma ou concepção comum é atribuída a Deus e não ao homem; ela é a Ideia que Deus tem de suas próprias obras (o homem, a pedra, a alma), definidas como "estados gerais ou especiais da natureza", e que, portanto, são naturais e não artificiais como as obras humanas (casa, espada) (LI, p. 66).

Somente Deus possui um perfeito conhecimento desses estados (status) de natureza, pois, o conhecimento do homem, realizado sempre por meio das sensaçóes, não "concebe de modo puro as naturezas das coisas" (LI, p. 66).

Deus, porém, a quem todas as coisas que criou são patentes por si mesmas, e que as conheceu antes que existissem, distingue cada um dos estados [status] em si mesmo e a sensação não é empecilho para Aquele que é o único a possuir verdadeira inteligência ( $L I$, p. 66).

Todavia, os nomes das coisas existentes engendram intelecção pois foram impostos segundo algumas naturezas ou propriedades das coisas, ainda que seu descobridor não tivesse delas um conhecimento adequado. Os nomes universais significam as formas comuns, "os quais, embora sejam de significação confusa quanto às essências denominadas, dirigem imediatamente o espírito do ouvinte para aquela concepção comum, assim como os nomes próprios para a coisa única que eles significam." (LI, p. 67).

Assim, são as ideias divinas que garantem a legitimidade da significação das formas comuns através dos nomes universais; os gêneros e as espécies não são uma classificação artificial instituída pelo homem para fins utilitários; são nomes que traduzem uma ordem natural de estados de natureza concebida por Deus. "Para o nominalismo de Abelardo, que se insere numa tradição aristotélica, gêneros e espécies não formam uma classificação artificial relativa à utilidade humana; eles traçam a ordem das substâncias, a classificação natural” (Vignaux, I93I, col. 73I). Desse modo, Deus cria os estados gerais ou específicos, gêneros e espécies enquanto naturezas ou realidades dereificadas, segundo uma relação ou ordem natural também concebida por Ele, animal como gênero da espécie homem.

A unidade de significação do nome universal conduziu Abelardo a um modo de ser ideal natural, não sensível. Ela é para ele como a lembrança da unidade e da simplicidade do Pensamento divino que conhece perfeitamente, em sua ordem e nos detalhes de sua singularidade, os estados e as naturezas das coisa que Ele criou. Fazendo apelo às ideias divinas para garantir nossa linguagem por gêneros e espécies, Abelardo deu assim um pano-de-fundo teológico à teoria do universal (Wenin, 1982, p. 443). 


\section{Conclusão}

À primeira questão levantada por Porfírio — se os gêneros e as espécies subsistem — Abelardo responde afirmativamente se por ela entendemos que gêneros e espécies "significam" algo existente: os universais significam, por denominaçấo, as mesmas coisas que os nomes singulares e engendram uma intelecçáo isolada, nua e pura, mas náo vazia. Em relação à segunda pergunta — se os subsistentes são corporais ou incorporais — entendido como separados ou não separados, Abelardo responde: são corporais na medida em que nomeiam coisas reais, ou seja, separadas; são incorporais quanto ao modo de significação porque "embora denominem o que é separado, náo o denominam separada e determinadamente" ( $L I$, p. 75$)$. Quanto à terceira questão - se se encontram nos sensíveis - Abelardo retoma a interpretação conciliatória entre Aristóteles e Platão:

Diz-se que os universais subsistem nos sensíveis, isto é, que significam a substância intrínseca existente na coisa sensível em virtude das formas exteriores e que, significando essa substância que subsiste em ato na coisa sensível, manifestam contudo a mesma como naturalmente separada da coisa sensível [...] (LI, p. 75).

Por fim, a célebre quarta questáo que Abelardo acrescenta, ou seja se o nome "rosa" significa algo quando não há mais nenhuma rosa, vimos já que o nome universal deixa de existir uma vez que deixa de ser predicado de muitos, mas, ainda assim, o nome rosa năo deixa de significar, porquanto engendra uma intelecção.

Para concluir, um outro problema - o dictum propositionis — náo abordado na Logica Ingredientibus e sim na Dialetica de Abelardo, talvez traga uma luz a mais para a caracterização de seu platonismo não-realista. ${ }^{15}$ Aqui, o que está em questão, não é mais o significado das palavras isoladamente, mas aquilo que é enunciado (dictum) por uma proposição. $\mathrm{O}$ dictum, diz Abelardo, não é uma res, mas um estado de coisas, ou mais precisamente, o modo como as coisas se relacionam entre si. Vimos já essa mesma caracterizaçáo a respeito da causa comum da imposiçáo dos nomes universais. Mas, ainda que não seja uma coisa, aquilo que é expresso por uma proposição é real uma vez que é através dele que se decide o verdadeiro e o falso:

"O homem corredor" não difere em nada, quanto à intelecção, de "o homem corre"; mas se falamos de enunciação verdadeira ou falsa, vai-se mais longe e o que nos faz ir mais longe é somente a segunda construção: na definição da proposiçáo, significar o verdadeiro ou o falso não deve ser compreendido quanto à intelecção, mas quanto ao que exprimem as proposiçôes (secundum dicta propositionum): a saber, apresentar num enunciado o que está na coisa ou não está na coisa (Jolivet, 1982, p. 80).

\footnotetext{
${ }^{15}$ Jolivet (1982, p.82, nota 126), indicando a falta de uma análise histórica do termo, sugere a aproximaçáo do dictum abelardiano ao $\lambda \varepsilon \kappa \tau$ ov estoico, ao complexe significabile dos ockhamistas do séc. XIV e, mais próximos de nós, às teorias de Meinong e de Husserl sobre o enunciado. Talvez seria preciso também incluir o conceito de acontecimento tal como concebido por Deleuze (1974, pp. 20-2I).
} 
Realidade dereificada, é esse estatuto do dictum que permite que nele resida a necessidade dialética. Com efeito, a necessidade das consequências lógicas náo pode ser atribuída nem às coisas nem às intelecçôes particulares, sujeita ambas às vicissitudes do tempo e à contingência. A consequência hipotética "se é homem, é animal" guarda sua necessidade mesmo que o mundo acabe ou mesmo que náo se pense nela: ela é garantida por uma relação eterna, por uma ordem natural ("animal é gênero de homem”) concebida pelo pensamento divino, não enquanto coisas, mas enquanto status. A existência eterna dos gêneros e das espécies enquanto puras essências denuncia o platonismo de Abelardo, sob a condição de entender a realidade dos universais enquanto status; longe, portanto, do modo de ser das coisas.

Dizer que o fundamento dos nomes universais e das proposiçôes hipotéticas eternamente verdadeiras é a mesma, a saber, as Ideias divinas interpretadas como status, tal é o platonismo de Abelardo, tal é também seu não-realismo. É, assim, a noção de status que constitui o coração da doutrina de Abelardo, de seu 'não-realismo platônico', esse status que não é uma coisa (donde o nãorealismo), mas que não é não mais a Ideia de uma coisa, esse status que é uma quasi res, uma 'quase coisa' expressa plenamente somente por uma proposiçáo infinitiva, esse quasi nomen, quase-nome, em que se manifesta, em sua dimensão verbal, a plenitude do ser que constitui o fundo de cada coisa (De Libera, 1996, p. I49).

\section{Referências bibliográficas}

Abelardo, P. (1994). Lógica para principiantes. Traduçáo de C. A. Ribeiro do Nascimento, Petrópolis: Vozes.

Bertelloni, F. (1988). "Pars construens, la solúcion de Abelardo al problema del universal en la $\mathrm{I}^{\mathrm{a}}$ parte de la Logica Ingredientibus'”. In: Patristica et Mediavalia (separata), vol. 7, Buenos Aires, pp. 49-64.

BerTelloni, F. (1995). "Status... quod non est res. Facticidade del status como fundamento de la universalización de lo real en Pedro Abelardo”, In: Mediavalia (separata), 7-8, Porto: Fundação Eng. António de Almeida.

Deleuze, G. (1974). Lógica do sentido. Tradução de L. R. S. Fortes. São Paulo: Perspectiva.

De Libera, A. (1993). La philosophie mediéval. Paris: PUF.

De Libera, A. (1996). La querelle des universaux. De Platon à la fin du Moyen Age. Paris: Seuil.

Gilson, E. (I995). A filosofia na Idade Média. Tradução de E. Brandão, São Paulo: Martins Fontes.

Jolivet, J. (1982). Arts du langage et théologie chez Abelard. Paris: Vrin.

VignauX, P. (I93I). "Nominalisme”, In: Dictionaire de Théologie Catholique, t. XI, Paris.

Wenin, C. (1982). "La signification des universaux chez Abélard”, In: Revue Philosophique de Louvain, LXXX, pp. 4I4-448. 